\title{
The Mind-Body Problem: The Perspective of Psychology
}

\author{
Shulamith Kreitler \\ School of Psychological Sciences, Tel-Aviv University, Tel-Aviv, Israel \\ Email:krit@netvision.net.il
}

How to cite this paper: Kreitler, S. (2018). The Mind-Body Problem: The Perspective of Psychology. Open Journal of Philosophy, $8,60-75$.

https://doi.org/10.4236/ojpp.2018.81006

Received: November 24, 2017

Accepted: February 25, 2018

Published: February 28, 2018

Copyright (C) 2018 by author and Scientific Research Publishing Inc. This work is licensed under the Creative Commons Attribution International License (CC BY 4.0).

http://creativecommons.org/licenses/by/4.0/

\begin{abstract}
The paper traces the changes in the conceptualization of body-mind relations in psychology in terms of five sequential phases. The first phase is characterized by the view that there is nothing but the body. The second phase is marked by the conception that the mind is the only relevant agent. The third phase is based on the view that both body and mind exist but are on parallel tracks. The main assumption in the fourth phase is that both body and mind exist and function in interaction. Finally, the major tenet of the fifth phase is that body and mind are identical. The role and status of cognition, emotion, and behavior in the five phases are discussed. The paper presents for each phase the main theoretical constructs and implications for empirical studies, as well as major research products and insights yielded in the frameworks defined in terms of each phase.
\end{abstract}

\section{Keywords}

Cognition, Emotion, Behavior, Interaction, Identity

\section{Introduction}

The mind-body problem is one of those issues with which many disciplines have to cope, sometimes repeatedly. It is necessary to deal with it because it is of central importance for many other issues in diverse disciplines. In many disciplines it is possible to distinguish between the basic theoretical understructure of assumptions that remains often implicit, and the theoretical background that is reflected more directly in the hypotheses and ideas that shape the investigator's work. The body-mind issue clearly belongs to the former level. Yet, it is not one of those issues that can be solved once and for all and be disposed of. Its solution depends a lot on the state of art at the time, which means it depends on what is known or accepted as known at the time, in different domains of science and 
thinking, as well as on the specific needs and goals of the particular domain of science at that time. Hence, the body-mind issue is here to stay for a long time since the state of knowledge changes and the needs of scientists and thinkers change. The paper deals with the various solutions that have been proposed to the mind-body problem in the course of modern psychology. These solutions are likely to shed light on the course of psychological research in the last decades as well as to prepare the ground for new insights and the elaboration of innovative approaches to this major issue of mind-body relations.

\section{The Metaphor for the Mind-Body Problem in Psychology}

Psychology as a science cannot be freed from the need to deal with the mind-body issue, primarily though not exclusively because it is officially the science of the mind. As will be clarified later, the issue was dealt with often in a quite stormy manner. It would not be inappropriate to compare the mind-body issue in psychology to the relations of a couple. The members of this couple are mind and the body. Since this couple landed in the territory of psychology it has undergone very troublesome relations. It seems that the ideal conception, shared by many psychologists, is that mind and body are bound together harmoniously. This conception is often unconscious, as well as the attached myth that the original state of bliss came to an end with a kind of an unfortunate event. One way to describe the narrative up to now is in terms of the Humpty Dumpty story. As is well-known, Humpty Dumpty sat on a wall and perhaps never thought that it included a mind and a body. But then it had a "great fall" and nothing was the same after that, because "all the king's horses and all the king's men" aided and encouraged by philosophers, psychologists and other scientists "could not put Humpty together again". The subsequent phases of the relations between mind and body constitute a narrative with phases such as separation, attempts at elimination of the partner, overlooking the partner's existence, behaving as if he/she/it does not exist, taking control of the other's possessions, attempts at negotiations, getting back together, recurrent divorce, unification, and slowly putting up with reality, and coming to terms with the inevitable situation defined by the realization that survival of each depends on cultivating the bond.

At this point, the story changes location from myth and literature to psychology.

1) Phase one: There is nothing but the body

Psychology as a topic of interest has existed in most cultures from very early times, but as a modern science it was established only at the beginning of the $20^{\text {th }}$ century. This first phase was characterized by the approach that there is only the body. The dominant psychologists of that period (Hull, 1943; Skinner, 1938; Watson, 1930) belonged to the trend known as behaviorism, which meant that the focus of interest was behavior-the external observable behavior or the internal behavior that corresponds to the physiological. There were different advantages to focusing only on behavior as the material or subject matter of psy- 
chology. First, since behavior is an object that may be assessed relatively easily and in a standard manner which conforms to the requirements of the life sciences, focusing on behavior enabled behaviorism to flaunt the belongingness of psychology to the "hard" and "serious" sciences. The standard experiment became a setup including a clearly identified stimulus and the reaction was a simple defined behavior such as moving a limb or secreting saliva. These components constituted the core of the stimulus-response paradigm that dominated psychological research for several decades. Secondly, the selection of behavior as the central theme of psychology implied the dissociation of psychology from the traditional themes of inquiry based on introspection and mental processes and announced the new phase or new beginning of psychology. A third advantage was that dealing with behaviors formed an easy bridge to physiology which was esteemed as "scientific" even more than behavior. The physiology that seemed accessible referred in the beginning phase to muscular reactions, which were close if not actually identical to so-called "behavior". A fourth advantage was that denying psychological processes made it possible to give up the need to use human beings as subjects for experiments. Behavior and physiological reactions can be assessed and manipulated experimentally better with animals (e.g., rats, mice, monkeys) without the restrictions which apply in regard to humans. The results of experiments with animals were generalized as if they apply directly to human beings. It was only later that the possible limitations of these generalizations were noted. Studies showed that animal models may not be perfect basis for conclusions about humans no more in psychology than in biology (Shanks, Greek, \& Greek, 2009).

Behaviorism assumed that all so-called psychological processes, such as cognition or emotional experience, are reducible to behaviors or physiological events. For example, an attempt was made to define thinking as subvocal movements of the throat muscles (Reese, 2000). However, a large body of data showed that the relations of language and thought are more complex and that thought cannot be reduced to language (Gleitman \& Papafragou, 2014). The basic assumption was that there are no psychological processes that deserve to be identified as psychological or justify any attention on the part of researchers or therapists. The claim was that actually there are no psychological processes at all and that which seems to qualify as psychological are in fact irrelevant fumes of basic underlying physiological processes. Notably, at about the same time the psychoanalytic approach, which placed a lot of emphasis on psychological processes, also considered for very different reasons cognitions as irrelevant rationalizations (Freud, 1933). As a result of the emphases on the body to the exclusion of the mind, the body of data about cognition and mental processes in general did not grow appreciably.

In the framework of psychology, the major scientific contributions of the physical monism approach were the development of experimental paradigms of research based on clear definition of variables and definite manipulations, whose effects are assessable in terms of fairly advanced statistical procedures. Learning 
was the major domain of studies, and the theme was explored in terms of stimuli, responses and provided reinforcements (e.g. Hilgard \& Bower, 1966; Hull, 1940). Additionally, the studies inspired by this approach led to clarifying the nature and role of basic units of behavior such as the reflexes and conditioned reflexes, identifying fundamental bonds between behavioral units or processes, and laid the groundwork for the exploration of physiological processes on higher levels, mainly the neural networks and the brain.

2) Phase two: The mind is the only relevant agent

It is not surprising that another phase of the mind-body relations is a parallel monistic approach which focuses only on the mind. The basic assumption is that "everything is in your mind". Thus, the proponents of this approach claim that the determinants of behaviors of all kinds and physiological processes are grounded in psychological processes of the following kinds; emotions, desire, cognitions, imagination, volition, and decisions. They do not deny the existence of physiological processes but they deny the hypothesis that they are the determinant of anything relevant on the psychological level. If a person decides something or really wants something to happen, that thing actually happens. This applies also to processes involved in health and illness. These states too are assumed to depend on psychological forces. Hence, in order to stay healthy or become healthy in cases of physical disorder, what is required is to believe whole-heartedly and focus on the goal. Practices designed to enhance spirituality and cleanse the body and the soul may be of assistance for promoting the end. The powers of the soul may help a person attain any goal, changing reality and shaping one's physiological processes. Physiological processes exist but they are weaker than the spiritual forces which may be engaged for directing and ruling physiology. The reliance on physiology for explaining or attaining one's desired goals is erroneous and inefficient.

Recent examples that are often mentioned by the proponents of so-called spirituality are guided imagery and positive psychology. Guided imagery is used for demonstrating that when one asks for the right things by applying the right procedure of positive-phrased imagery the stated goals are accomplished (Kreitler, 2012). Positive psychology is an approach that advocates concentrating one's cognitions and feelings mainly on the positive aspects of life in order to get positive outcomes (Mahoney, 2002). Failure in attaining the desired goals is attributed to incomplete or incorrect application of the guided imagery procedures or lack of faith in the poser of spirituality. The message is that psychological self-control is actually a major means for attaining control of the external and internal sphere of existence.

In the framework of psychology the major scientific contributions of this kind of psychological monism were better identification of the nature and role of psychological processes, mainly cognitive, including attitudes, values, schemes, concepts, and imagery as well as processes involved in problem solving, night dreams, daydreams, or creativity (e.g., Csikszentmihalyi, 1990; Hall, 1953; Ne- 
well \& Simon, 1972; Singer, 1975). The contributions of adopting the approach of pure psychological monism included high-level studies in cognition, in emotions and in personality (Kreitler, 2004). Since cognition was considered as the quintessence of the mind, a lot of research focused on cognition and on the involvement of cognitive contents and processes in emotions and personality was explored (Kreitler \& Kreitler, 1990). Further evidence for the status of cognition is the emphasis in research on cognitive theories of motivation-developing the constructs of goals, intentions, and attitudes (Kreitler, 2004). In this context the study of interactions and mutual effects of the different psychological processes, such as the impact of personality or emotions on cognition, was given priority (e.g., Judge, Higgins, Thoresen, \& Barrick, 1999; Pekrun, 1992).

3) Phase three: Body and mind are on parallel tracks

Phase three is characterized by a dual recognition of the two entities: both mind and the body are granted a license for existence but they are not assumed to be related in any way. The situation resembles two individuals who inhabit the same house but have stopped talking to each other many years ago. Yet, in some inexplicable sense there is a feeling or an intuition that they have something in common or simply that they belong together. In more abstract terms, the situation of body and mind in phase three may be characterized as autonomous co-existence. The two entities are however considered to be completely different, functioning in accordance with different rules: the mind according to mental or spiritual rules, the body according to material or physiological/biological rules (grounded in chemical and physical processes). Hence they cannot be expected or assumed to interact.

This phase can be characterized as a double monism, for each of the two entities of body and mind exists as it were in its own territory without bothering or being bothered by the other entity. Theoretically this kind of "double monism" is an easier approach than the single monism which focuses on upholding only the existence of the body or of the mind, because fewer resources need to be expended on denying the existence of the other or refuting considerations supporting the other's existence and impact.

In the world of double monism the proponents of each of the two entities focus on the functioning of the entity they support, with full justification of their selective approach. Regardless of the theme that is being studied, the supporters of double monism declare implicitly or even explicitly that they have chosen to study it from the particular perspective which they represent, although they are aware that there exists another perspective which may be as legitimate and potentially as fruitful as the one they represent.

For example, when the theme is mental disorders, the proponents of the mind may study pathological thinking features in schizophrenics, such as impaired verbal memory (McGurk et al., 2004) or overgeneralization (Talreja, Shah, \& Kataria, 2013), attitudes of depressives (Dobson \& Franche, 1989) or behaviors of psychopathic patients (Hare \& McPherson, 1984). On the other hand, in a 
completely separate camp, there are the body-minded researchers who may focus on studying physiological aspects of schizophrenia which may or may not be related to the psychological aspects of the disorder, such as dopamine and serotonin (Cronenwett, 2016), or GAD and GABA synthesis gene in the prefrontal cortex of schizophrenics (Mitchell, Jiang, Peter, \& Akbarian, 2015). The investigators in each camp focus on their studies, nurtured by their limited but well-defined perspective, without referring or worrying about the investigators in the other camp, of whose actions they may be aware but do not always manifest understanding for them. Sometimes some relation may be noted between the studies from the different camps by the respective investigators themselves or the readers, but more often than not the relations are not elaborated and may even be due to random occurrences.

4) Phase four: Body and mind exist in interaction

Phase four is characterized by the conception that body and mind constitute two systems in interaction. One implication of this approach is that although the two entities are autonomous neither one can be fully and adequately understood without considering the impact of the other entity on it. The source, the triggers, the manner of operation, the outcomes, and the manifestations of the two kinds of impact-of body on mind and of mind on body-are expected to differ in various respects. However, although it is rarely stated explicitly, both kinds of impact are assumed to be equally potent and important.

One implication or result of this kind of thinking is the tendency to consider the interacting entities as not simply structures but as systems. The reason is that systems are more amenable for interactions because they are conceptualized in terms of multiple components that may include aspects more likely to bond with or react to the effects of components in the other system. An affiliated implication is that the systems representing body and mind are in dynamic states. This feature too enables and promotes interaction and may also result from interaction. Finally, the conception of two systems in interaction requires considering the realm in which the two systems exist and which supports the interaction. Hence, the third implication of the two-systems-in interaction is considering the context, which may be the external environment (as in ecological perception) or the internal environment (as in sensorimotor cognition), or the group (as in social psychology) or the audience (as in communication studies).

Some examples of the better known interactions may clarify the body and mind interactional approach. There are many examples of the impact of body on mind. Some of the simpler examples are that physical states such as lack of sleep, hunger, cold and pain affect the thinking of the individual by decreasing concentration and reducing the creativity and possibly the rationality of the thoughts at the time (Kreitler \& Niv, 2007). The interactional approach is supported by many studies showing the effects on cognition of psychological processes, such as motivations and emotions or physiological ones, such as genes (Kreitler, 2013a). There is a long list of physical disorders which were found to affect ne- 
gatively cognitive functioning, including cardiological, hematological, gastroenterological, dermatological, hormonal, neurological and malignant (Kreitler, Weissler, \& Barak, 2013). Physical disorders may affect the mind, for example, through produced hormones, reduction of oxygen to the brain, or destruction of tissue, as well as through evoked reactions including depression or demoralization. In addition, the mind including cognition, emotions and motivation are seriously affected by sensory disabilities such as difficulties in sight, hearing and even smelling, bodily states such as being pregnant or overweight, and medical treatments, including the short and long-term effects of surgery, chemotherapy and drugs, such as antihypertension and statins (Kreitler et al., 2013). The effects of all these and similar body-anchored or body-targeted procedures on the mind are due to direct effects, side effects and even psychological effects, such as anxiety or depression or anger evoked by the disorders or the treatments. No less impressive examples for the effect of body on mind refer to the improvement in the cognitive functioning and emotional state of individuals engaged in physical training (Angewaren et al., 2008; Zhu et al., 2014). These latter effects might have led to the not always true quote about "the healthy mind in a healthy body" known since antiquity.

More sophisticated examples include the studies known as embodied cognition demonstrating that the state of the body, including perception, muscles and posture, affects or reflects on the concurrent thoughts (Barrett, 2011; Pfeifer \& Bongard, 2012). Claxton (2015) cites examples of studies demonstrating that holding cold packs in one's hands is reflected in acting coldly toward one's friends, that people sitting upright are more aggressive in gambling than those assuming a slouched posture. Further, leaning to the left causes underestimating the size of things because it evokes the left hand end of the number line (Earland, Guadalupe, \& Zwann, 2011).

No less challenging and interesting are the examples of research in the context of embodied cognition demonstrating the impact of mind on the body. For example, due to underlying common metaphors, thinking about the future may cause swaying forward whereas thinking of the past causes swaying backwards (Miles, Nind, \& Macrae, 2010).

A most important example of the effect of mind on the body is the evocation and orientation of behaviors. Several attempts to prove this effect such as the model of achievement motivation (Atkinson \& Feather, 1966), the model of reasoned action (Fishbein \& Ajzen, 1975) the health belief model (Becker, 1974) have failed due to faulty assumptions, mainly that the effects of the mind should be based on rational and conscious decisions, and weighing of costs and benefits. Further, the predicted outputs of these models are declared intentions, which are not to be equated with behaviors but rather with cognitions. Thus, these models did not cross the gap between a declared intention and an actually performed behavior.

The approach of cognitive orientation has been successful in developing a 
theory and a methodology for understanding, predicting and changing behaviors. The part of the mind is represented by cognitions and the part of the body is represented by actually performed behaviors. The cognitions that have proved useful and adequate for predicting behaviors are of a particular kind. These are beliefs of four types: beliefs that refer to oneself describing, for example, one's traits or habits and different facts (e.g., I often come late to meetings and appointments); beliefs that refer to standards and norms, describing what should or should not be done from an ethical, practical or esthetical point of view (e.g., One should not be late for appointments); beliefs about goals, referring to goals or wishes of the person for things and states one wants or does not want (e.g., I want to be able to be always on time), and general beliefs that refer to things one believes apply or do not apply to people or situations in reality (e.g., Coming late may harm one's reputation). The beliefs that play a role in behavior evocation, i.e., those that are used for predicting behavior in experimental setups, do not refer directly to the behavior but to themes that reflect the deeper underlying meanings of the behavior of interest which can be identified by a standardized procure (Kreitler \& Kreitler, 1976, 1982). The beliefs that refer to the relevant themes form a motivational disposition that orients toward the particular behavior, as shown in Figure 1. This motivational disposition is not based necessarily on rational considerations and is not conscious or under voluntary control. However, in order to produce an actual behavior, there must be a behavioral program that implements the motivational disposition. The program is a hierarchically structured sequence of steps governing the performance of the act, in terms of strategy and tactics, on the physiological and motor levels. The motivational disposition is on the level of the mind. But if it is implemented by a behavioral program, an act of behavior-which is on the level of the body-is evoked. The motivational disposition has enabled predicting a large set of behaviors,

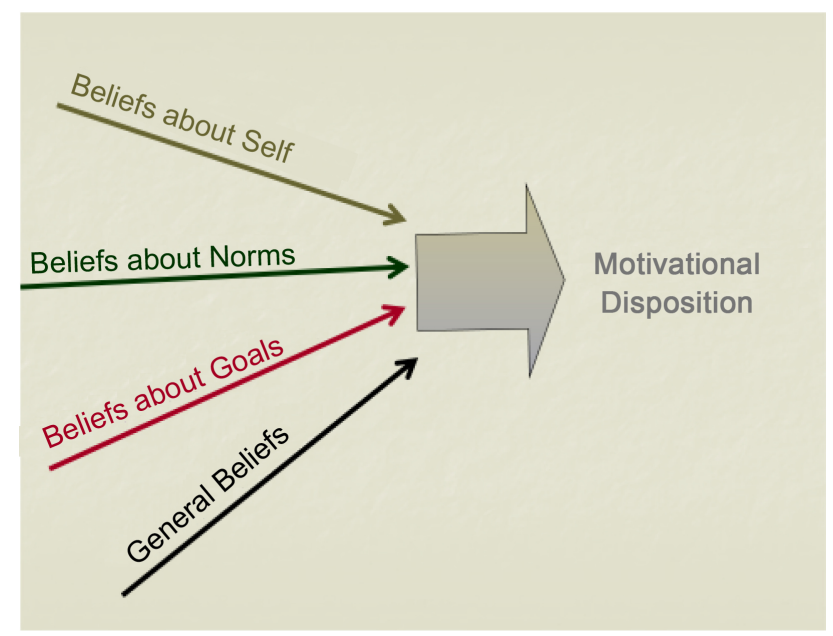

Figure 1. The vector of the four types of beliefs generating the motivational disposition (according to the cognitive orientation theory, Kreitler, 2004). 
ranging from reactions to success and failure or coming on time, anger expressions, helping others, and even addictions and psychopathological behaviors (e.g., Kreitler, 1999; Kreitler, 2013b; Kreitler, 2013c; Kreitler \& Kreitler, 1982).

Recent neurological studies showed that the mind affects the reactions of the brain in ways that may be clearly manifested in external behavior. Several motor areas of the cerebral cortex involved in the planning and performance of movement are linked to and control the functioning of the adrenal medulla (Richard, Dunn, Levinthal, \& Strick, 2016). This implies that the cortex plays an important role in determining which action will follow the evocation of stress, e.g., fight or flight or another action supported by a cognitively based motivational disposition. In other words, the mind shapes the stress evocation as well as the responses of the brain and its overt motor responses to the stress.

Another domain in which the impact of mind on the body has been amply studied concerns physical diseases. It is common knowledge that the mind can bring about physical symptoms, such as dry mouth, palpitations, fast heart rate and shaking in a state of fear or anxiety, or blushing and sweating in a state of embarrassment. Stress too can bring about the evocation of a whole range of physical symptoms, evoked by nervous impulses from the brain to various parts of the body and to processes such as hormone release, e.g., epinephrine. The persistence and recurrence of reactions of this kind over a long time may even bring about a transformation of the functional changes to structural changes in the body.

Studies showed that traumatic stress, which involves responses in the amygdala, hippocampus and prefrontal cortex, may bring about lasting changes in these areas (Bremner, 2006), Thus, post-traumatic stress is related to a reduction in the volume of the hippocampus, a brain area involved in learning and memory (Bremner, 1999), as well as to reduced gray matter volume in the hippocampus and the and also in the medial prefrontal cortex (Cheng et al., 2015).

The major thesis of psychosomatic medicine is that emotional factors or stress may result in physical diseases. In its strong form the psychosomatic thesis is that the mind is the sole cause of diseases and it may also be the sole or major factor in recovery. The diseases most often mentioned in this context have been gastrointestinal and dermatological disorders, asthma, and cancer (e.g., Spiegel, Bloom, Kraemer, \& Gottheil, 1989). The greater part of the studies presented as evidence was actually based on correlations between psychological and physical variables, which do not support any causal argument. Some studies clearly refuted the psychosomatic claim (e.g., Coyne, Stefanek, \& Palmer, 2007). In addition to the empirical difficulties there have also been theoretical difficulties, mainly the unclarity of criteria for distinguishing between a physical disorder (e.g., asthma) caused by physical factors and an apparently similar physical disorder caused by psychological factors.

The cognitive orientation theory has led to an innovative approach to the issue of the effect of the mind on the body in the domain of physical disorders. 
The cognitive orientation model of physical disease and health is based on the assumption that each physical disorder is caused by a physical pathogen, which may be a virus, a microbe or some chemical or physical factor. However, the mere encounter between a pathogen and the living tissue or organism does not automatically bring about the occurrence of a disease. A major role is played by risk factors of different kinds, such as nutritional, anatomic, hormonal, immunological and psychological, as shown in Figure 2. Psychological risk factors are assumed to be involved in every kind of disorder. However, this involvement means only that the psychological factors together with other risk factors affect to some extent the occurrence of the disease and its course. Risk factors play a role regardless of the severity of the pathogen. Further, just as a pathogen for one disease does not instigate another disease, the risk factors too are mostly specific for the disorder. Thus, cholesterol levels are a risk factor for cardiological disorders, but not for cancer. Similarly, the psychological risk factors are specific for each disease (Kreitler, Kreitler, \& Barak, 2013). Moreover, in some cases the risk factors involved in affecting the course of disease are not identical to those that affect its occurrence. The emphasis on the specific nature of the risk factors clarifies that the construct of stress cannot serve as an adequate explanation for the impact of mind on body in the context of diseases. The reason is that stress is a too general term: what causes stress relevant in regard to one kind of disease cannot be assumed to cause stress in the context of another disease. For example, a large load of work may be stressful for individuals with cardiological disorders, but no work demands may be stressful for individuals with tendencies for psoriasis (Figer, Kreitler, Kreitler, \& Inbar, 2002).

The psychological risk factors are not psychiatric tendencies but personality characteristics that are either difficult to implement in themselves (e.g., a tendency to be always evaluated positively by everyone or to avoid all uncertainties) or are contradicted by another tendency thus forming a kind of conflict with it

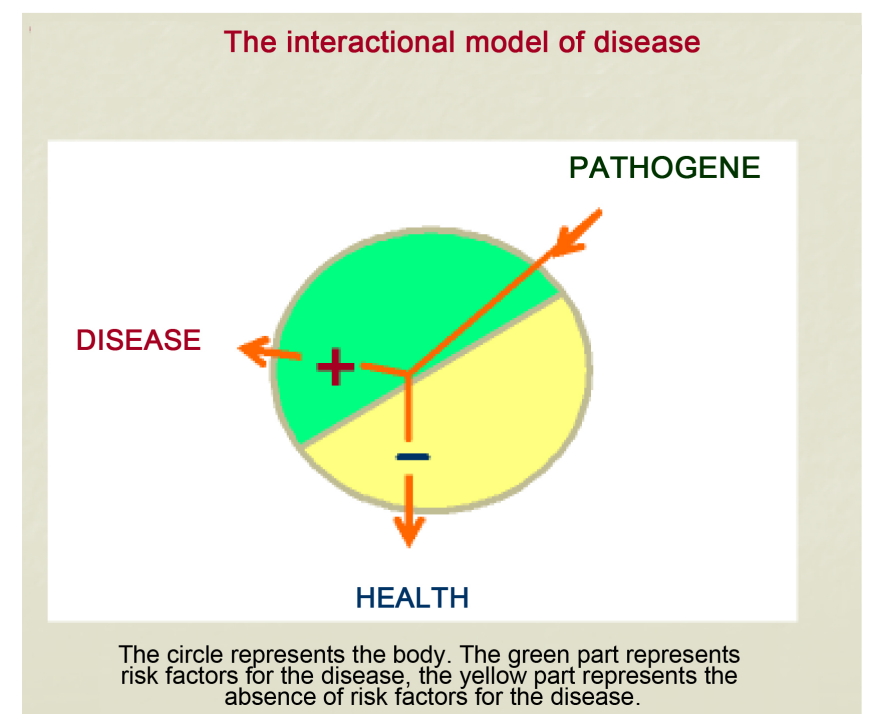

Figure 2. The interactional model of disease. 
(e.g., the tendency to keep complete harmony in all family relations and the tendency to control the behavior of close family members). Notably, the disease-generating conflicts are mostly of a recurrent kind that cannot be resolved by one simple action such as eating or not eating a piece of cake.

The cognitive orientation theory has led to the development of a specific methodology for the identification of the risk factors relevant for a physical disorder. It is based on a systematic stepwise meaning probing and leads to the identification of the deeper meanings underlying the overt surface manifestations of the physical outputs. When these meanings are formulate in the form of the four belief types (about oneself, about others and reality, about norms and about goals) they form the motivational disposition for a disorder that is similar to the four pronged vector that orients toward a specific overt behavior. Again, as in regard to overt behaviors, the motivational disposition is neither necessarily based on rational beliefs or considerations, nor conscious or under voluntary control. Studies based on this approach led to significant results in regard to diseases such as colorectal cancer, diabetes, asthma, or disorders indicative of impaired system of immunity (Kreitler, 2016). The beliefs orienting for each disorder were specific for that disorder (Kreitler, Kreitler, \& Barak, 2013).

5) Phase five: Body and mind are identical

The mind-body identity approach is difficult to describe and no less difficult to implement. It is based on the claim that body and mind are not separate at all, but are actually the same entity, or they form one entity. Attempts to formulate this insight have led to erroneous or misleading conclusions that either integrated the mind into the body, or the body into the mind, namely, the probably unintentional result was a version of the physicalism discussed as Phase one or mentalism, discussed as phase two (above).

Attempts to express the conception more accurately have led to statements such as "the brain process is identical to the mental process of consciousness", or "pain is the same as C-fiber activation", or "visual consciousness is identical to firing of neurons in area V1 of the human cerebral cortex" (Place, 1956; Feigel, 1967). Regardless of how correct these statements may be, they solve very little by way of clarifying the features or functions of the equated phenomena and are actually identical to the approach of phase three about the parallelism of body and mind.

Part of the difficulty may be that we do not have the proper kind of language to refer to a mind-body unit. Even an apparently right term like psychophysics leaves the dualism in the construct. The same can be claimed in regard to the more modern term neuropsychoimmunology which is a kind of a tripod conglomerate. There are several metaphorical attempts to describe the body-mind unity, for example, they are two aspects of a crystal that may appear to differ when we move or assume a different perspective. Another metaphor for describing the issue may be based on the optical illusion of "Rubin's vase" which consists of two identical symmetrical profiles facing one another that cannot be viewed simultaneously but form together the shape of a vase, as shown in Figure 3. The implication is that the identity approach requires the construction of a 


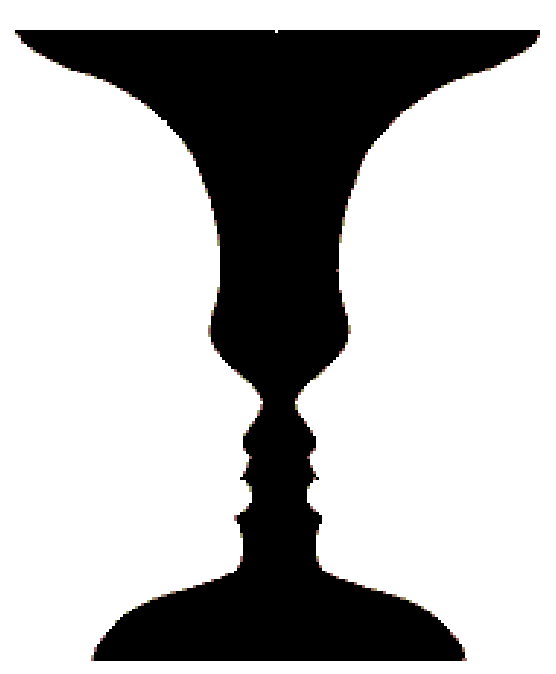

Figure 3. "Rubin's Vase": this optical illusion consists of the outlines of two symmetrical profiles facing each other. They cannot be viewed at the same time. They form the outlines of a vase when one focuses on the center and disregards the two profiles.

higher-level concept to which both identical figures contribute.

A common approach to the issue is based on the conception of multileveledness which would place mind and body on different levels. This suggestion is perhaps inspired by analogies with other contexts, mainly language, social sciences and physical sciences. In language there is a differentiation between the levels of phonology, morphology, syntax, semantics and pragmatics. In the social sciences the levels could be defined as psychology, sociology, and politics. In the physical sciences, the identified levels could be physics, chemistry, and physiology. In all three examples, on each level the units as well as the rules of operation are different. All levels are indispensable for describing, analyzing, understanding and changing the overall construct, be it language or the social and physical sciences. The levels are ordered in a hierarchical sequence that reflects their interdependence. Thus, for example, the level of chemistry cannot exist without physics but the rules and units of chemistry cannot be derived from those of physics. Moreover, the dependence of one level on the lower one is not the same for all levels in the specific hierarchy. When the multileveledness approach is applied in regard to mind and body it is necessary to assume which one of the two constituents-mind or body-is on the lower level. This decision as such clarifies that multileveledness is barely a good resolution because it sets mind or body on a level that is considered a lower or more fundamental. It may not be superfluous to mention at the point the constructivist approach according to which the sphere in which both mind and body are assumed to exist and function is the result of meaning construction (Kreitler, 2014). Given that reality is the product of the interactions between environmental inputs and the cognitive activities of the human mind, it needs to be realized that both mind and body are 
based on meaning, and shaping further meaning-based constructs, and systems, expressing and serving the promotion of knowledge.

The above discussion shows that what is needed for handling the conception of the identity of body and mind is a comprehensive construct on a higher level of abstraction that could encompass body and mind together and shed light on their static and dynamic integrations. A construct of this kind could be holistic or from a completely different domain of discourse than body or mind. When this construct is identified or created, it will enable the freedom of construction for the emergence of body and or mind or both and will provide new insights that may make it possible to answer the question whether the identity conception of body and mind has uncovered new vistas where "no man has walked before".

\section{References}

Angewaren, M., Aufdemkampe, G., Verhaar, H. J. J., Aleman, A., \& Vanhees, L. (2008). Physical Activity and Enhanced Fitness to Improve Cognitive Function in Older People without Known Cognitive Impairment (Review). Cochrane Database System Review, No. 2, Article ID: CD005381. https://doi.org/10.1002/14651858.CD005381.pub3

Atkinson, J. W., \& Feather, N. T. (1966). A Theory of Achievement Motivation. New York: Wiley.

Barrett, L. (2011). Beyond the Brain: How Body and Environment Shape Animal and Human Minds. Princeton, NJ: Princeton University Press.

Becker, M. H. (1974). The Health Belief Model and Personal Health Behavior. Health Education Monographs, 2, 324-508. https://doi.org/10.1177/109019817400200407

Bremner, J. D. (1999). Alterations in Brain Structure and Function Associated with Post-Traumatic Stress Disorder. Seminars in Clinical Neuropsychiatry, 4, 249-256.

Bremner, J. D. (2006). Traumatic Stress: Effects on the Brain. Dialogues in Clinical Neuroscience, 8, 445-461.

Cheng, B., Huang, X., Li, S., Hu, X., Luo, Y., Wang, X., Yang, X., Qiu, C., Yang, Y., Zhang, W., Bi, F., Roberts, N., \& Gong, Q. (2015). Gray Matter Alterations in Post-Traumatic Stress Disorder, Obsessive-Compulsive Disorder, and Social Anxiety Disorder. Frontiers in Behavioral Neuroscience, 9, 219. https://doi.org/10.3389/fnbeh.2015.00219

Claxton, G. (2015). Intelligence in the Flesh: Why Your Mind Needs Your Body Much More than It Thinks. New Haven, CT: Yale University Press.

Coyne, J. C., Stefanek, M., \& Palmer, S. C. (2007). Psychotherapy and Survival in Cancer: The Conflict between Hope and Evidence. Psychological Bulletin, 133, 367-394. https://doi.org/10.1037/0033-2909.133.3.367

Cronenwett, W. J. (2016). Schizophrenia Pharmacology: Past, Present and Future Targets for Intervention. Schizophrenia: Advances in Understanding and Treatment, 14, 308-314.

Csikszentmihalyi, M. (1990). Flow: The Psychology of Optimal Experience. New York: Harper \& Row.

Dobson, K., \& Franche, R.-L. (1989). A Conceptual and Empirical Review of the Depressive Realism Hypothesis. Canadian Journal of Behavioural Science, 21, 419-433. https://doi.org/10.1037/h0079839 
Earland, A., Guadalupe, T. M., \& Zwann, R. A. (2011). Leaning to the Left Makes the Eiffel Tower Seem Smaller: Posture-Modulated Estimation. Psychological Science, 22, 1511-1514. https://doi.org/10.1177/0956797611420731

Feigel, H. (1967). The "Mental" and the "Physical" the Essay and a Postscript. Minneapolis, MN: University of Minnesota Press.

Figer, A., Kreitler, S., Kreitler, M., \& Inbar, M. (2002). Personality Dispositions of Colon Cancer Patients. Gastrointestinal Oncology, 4, 81-92. https://doi.org/10.1080/1475956021000015095

Fishbein, M., \& Ajzen, I. (1975). Belief, Attitude, Intention and Behavior: An Introduction to Theory and Research. Reading, MA: Addison-Wesley.

Freud, S. (1933). New Introductory Lectures on Psychoanalysis. London: Hogarth Press and Institute of Psycho-Analysis.

Gleitman, L., \& Papafragou, A. (2014). Relations between Language and Thought. In D. Reisberg (Ed.), The Oxford Handbook of Cognitive Psychology (pp. 504-523). Oxford: Oxford University Press.

Hall, C. S. (1953). A Cognitive Theory of Dreams. The Journal of General Psychology, 49, 273-282. https://doi.org/10.1080/00221309.1953.9710091

Hare, R. D., \& McPherson, L. M. (1984). Violent and Aggressive Behavior by Criminal Psychopaths. International Journal of Law and Psychiatry, 7, 35-50. https://doi.org/10.1016/0160-2527(84)90005-0

Hilgard, E. R., \& Bower, G. H. (1966). Theories of Learning. New York, NY: Meredith Publishing Company.

Hull, C. L. (1940). Mathematico-Deductive Theory of Rote Learning: A Study in Scientific Methodology. New Haven, CT: Yale University Press.

Hull, C. L. (1943). Principles of Behavior: An Introduction to Behavior Theory. Boston, MA: Appleton Century.

Judge, T. A., Higgins, C. A., Thoresen, C. J., \& Barrick, M. R. (1999). The Big Five Personality Traits, General Mental Ability, and Career Success across the Life Span. Personnel Psychology, 52, 621-652. https://doi.org/10.1111/j.1744-6570.1999.tb00174.x

Kreitler, H., \& Kreitler, S. (1976). Cognitive Orientation and Behavior. New York, NY: Springer Publishing.

Kreitler, H., \& Kreitler, S. (1982). The Theory of Cognitive Orientation: Widening the Scope of Behavior Prediction. In B. Maher, \& W. B. Maher (Eds.), Progress in Experimental Pesonality Research (pp. 101-169, Vol. 11). New York, NY: Academic Press.

Kreitler, S. (1999). The Cognitive Orientation for Health: A Tool for Assessing Health-Proneness. In R. Schwarzer (Ed.), Advances in Health Psychology Research. Berlin: Freie Universitaet Berlin.

Kreitler, S. (2004). The Cognitive Guidance of Behavior. In J. T. Jost, M. R. Banaji, \& D. A. Prentice (Eds.), Perspectivism in Social Psychology: The Yin and Yang of Scientific Progress (pp. 113-126). Washington DC: American Psychological Association.

Kreitler, S. (2012). Guided Imagery: A Psychological Tool in the Service of Health Psychology. In K. R. Carter, \& G. E. Murphy (Eds.), Alternative Medicine: Practices, Health Benefits and Controversies (pp. 1-26). Hauppauge, NY: Nova Publishers.

Kreitler, S. (2013a). Cognition and Motivation: Forging an Interdisciplinary Perspective. New York, NY: Cambridge University Press.

Kreitler, S. (2013b). The Cognitive Orientation Approach to Psychopathology. In C. Pracana, \& L. Silvia (Eds.), International Psychological Applications Conference and Trends (pp. 431-432). Lisbon: World Institute for Advanced Research and Science 
(WIARS).

Kreitler, S. (2013c). The Cognitive Orientation of Addictive Behaviors. In C. Pracana, \& L. Silvia (Eds.), International Psychological Applications Conference and Trends (pp. 52-56). Lisbon: World Institute for Advanced Research and Science (WIARS).

Kreitler, S. (2014). Meaning and Its Manifestations: The Meaning System. In S. Kreitler, \& T. Urbanek (Eds.), Conceptions of Meaning (pp. 3-32). Hauppauge, NY: Nova Publishers.

Kreitler, S. (2016). The Motivation for Health: What Is It and How to Assess It. In C. Pracana, \& M. Wang (Eds.), InPACT International Psychological Applications Conference and Trends: Proceedings (pp. 172-176). Lisbon: World Institute for Advanced Research and Science WIARS.

Kreitler, S., \& Kreitler, H. (1990). The Cognitive Foundations of Personality Traits. New York, NY: Plenum. https://doi.org/10.1007/978-1-4899-2227-4

Kreitler, S., \& Niv, D. (2007). The Effects of Chronic Pain on Cognitive Functioning. Pain: Clinical Update, 15, 1-4.

Kreitler, S., Kreitler, M. M., \& Barak, F. (2013). Psychosocial Risk Factors of Cancer Diseases: How Specific Are They? Open Journal of Social Sciences, 1, 81-86.

Kreitler, S., Weissler, K., \& Barak, F. (2013). Physical Health and Cognition. In S. Kreitler (Ed.), Cognition and Motivation: Forging an Interdisciplinary Perspective (pp. 238-269). New York, NY: Cambridge University Press.

Mahoney, M. J. (2002). Constructivism and Positive Psychology. In C. R. Snyder, \& S. J. Lopez (Eds.), Handbook of Positive Psychology (pp. 745-750). New York, NY: Oxford University Press.

McGurk, S. R., Coleman, T., Harvey, P. D., Reichenberg, A., White, L., Friedman, J., Parrella, M., \& Davis, K. L. (2004). Working Memory Performance in Poor Outcome Schizophrenia: Relationship to Age and Executive Functioning. Journal of Clinical \& Experimental Neuropsychology, 26, 153-160. https://doi.org/10.1076/jcen.26.2.153.28079

Miles, L. K., Nind, L. K., \& Macrae, C. N. (2010). Moving through Time. Psychological Science, 21, 222-223. https://doi.org/10.1177/0956797609359333

Mitchell, A. C., Jiang, Y., Peter, C., \& Akbarian, S. (2015). Transcriptional Regulation of GAD1 GABA Synthesis Gene in the Prefrontal Cortex of Subjects with Schizophrenia. Schizophrenia Research, 167, 28-34. https://doi.org/10.1016/j.schres.2014.10.020

Newell, A., \& Simon, H. A. (1972). Human Problem Solving. New York, NY: Prentice, Hall.

Pekrun, R. (1992). The Impact of Emotions on Learning and Achievement: Towards a Theory of Cognitive/Motivational Mediators. Applied Psychology, 41, 359-376. https://doi.org/10.1111/j.1464-0597.1992.tb00712.x

Pfeifer, R., \& Bongard, J. C. (2012). How the Body Shapes the Way We Think: A New View of Intelligence. Boston, MA: M.I.T. Press.

Place, U. T. (1956). Is Consciousness a Brain Process? British Journal of Psychology, 47, 44-50.

Reese, H. W. (2000). Thinking as the Behaviorist Views It. Behavioral Development Bulletin, 9, 10-12. https://doi.org/10.1037/h0100531

Richard, P., Dunn, R. P., Levinthal, D. J., \& Strick, P. L. (2016). Motor, Cognitive, and Affective Areas of the Cerebral Cortex Influence the Adrenal Medulla. Proceedings of the National Academy of Sciences, 113, 9922-9927.

https://doi.org/10.1073/pnas.1605044113 
Shanks, N., Greek, R., \& Greek, J. (2009). Are Animal Models Predictive for Humans? Philosophy, Ethics and Humanities in Medicine, 4, 1-20.

Singer, J. L. (1975). The Inner World of Daydreaming. New York, NY: Harper \& Row.

Skinner, B. F. (1938). The Behavior of Organisms: An Experimental Analysis. New York, NY: Appleton-Century.

Spiegel, D., Bloom, J. R., Kraemer, H. C., \& Gottheil, E. (1989). Effect of Psychosocial Treatment on Survival of Patients with Metastatic Breast Cancer. The Lancet, 2, 888-891.

Talreja, B. T., Shah, S., \& Kataria, L. (2013). Cognitive Function in Schizophrenia and Its Association with Socio-Demographics Factors. International Psychiatry Journal, 22, 47-53. https://doi.org/10.4103/0972-6748.123619

Watson, J. B. (1930). Behaviorism (Revised Edition). Chicago, IL: University of Chicago Press.

Zhu, N., Jacobs, D. R. Jr, Schreiner, P. J., Yaffe, K., Bryan, N., Launer, L. J., Whitmer, R. A., Sidney, S., Demerath, E., Thomas, W., Bouchard, C., He, K., Reis, J., \& Sternfeld, B. (2014). Cardiorespiratory Fitness and Cognitive Function in Middle Age: The CARDIA Study. Neurology, 82, 1339-1346. https://doi.org/10.1212/WNL.0000000000000310 